\title{
El Concilio de Trento y las iglesias de la América española: la problemática de su falta de representación
}

\author{
Erika Tánacs \\ Pontificia Universidad Javeriana, Bogotá \\ tanacserika@freemail.hu
}

Fecha de recepción: 19 de septiembre de 2002

Fecha de aceptación: 1 de octubre de 2002

\begin{abstract}
Resumen
El tema de la falta de representación de la Iglesia hispanoamericana en las reuniones del Concilio de Trento ha sido analizado por algunos historiadores jesuitas desde los años cuarenta. La explicación se centró en los impedimentos objetivos, tales como la absoluta necesidad de la residencia de los obispos hispanoamericanos en sus diócesis, la enorme distancia y los peligros del viaje; en el sistema del Patronato Real, y en los escasos conocimientos que los padres conciliares tenían sobre los asuntos hispanoamericanos. La autora, sin embargo, considera que a la luz de recientes investigaciones sobre el Concilio y, más generalmente, sobre la época de la Reforma y la Contrarreforma se puede enriquecer la interpretación. Se intenta demostrar que, aunque los argumentos que presentan los padres Bayle, Leturia y Mateos tengan cierto valor y justificación, las razones se deben buscar, ante todo, en la coyuntura especial que determinó los objetivos del Concilio; en las expectativas y esperanzas que los obispos hispanoamericanos tenían, y en la lógica interna del Patronato Real que iba más allá de lo planteado por los mencionados autores.
\end{abstract}

Palabras clave: CONCILIO DE TRENTO, IGLESIA CATÓLICA, AMÉRICA ESPAÑOLA, SIGLO XVI, REFORMA, CONTRARREFORMA.

\begin{abstract}
Since the 1940's, several Jesuit historians have analyzed the topic of the lack of representation of the Hispanic American Church in the Council of Trent. The explanation they offer centers on the objective barriers, such as the absolute requirement that bishops reside within their diocese, the enormous distances involved, the dangers of the voyage; the Patronato Real system and the limited knowledge possessed by the fathers of the council regarding Hispanic american affairs. The author nevertheless considers that recent research regarding the Council, and more generally the time of the Reformation and Counterreformation, can enrich the analysis. Although the arguments presented by Frs. Bayle, Leturia and Mateos have a certain value and justification, the reasons must be found, above all, in the special conjuncture that determined the Council's objectives, in the expectations and hopes of the Hispanic American Bishops and in the internal logic of the Patronato Real that extended itself beyond the author's analysis.
\end{abstract}

Key words: COUNCIL OF TRENT, HISPANIC AMERICAN CHURCH, REFORMATION, COUNTERREFORMATION, $16^{\mathrm{TH}}$ CENTURY.

Fronteras de la Historia 7 (2002)

(C) ICANH 


\section{Introducción}

La problemática de la falta de representación de las iglesias hispanoamericanas en el Concilio de Trento llegó por primera vez a ser el centro del interés de los historiadores en los años 40 cuando, para celebrar el cuarto centenario de la inauguración del Concilio, se publicaron varios artículos y monografías sobre los más diversos aspectos de la gran asamblea religiosa. Fueron tres padres jesuitas, Constantino Bayle, Pedro de Leturia y Francisco Mateos, quienes, a propósito de esta celebración, por vez primera plantearon el problema de la ausencia de los obispos y de los temas religiosos de las iglesias de la América española en Trento. Desde la publicación de los trabajos, ya clásicos, de los mencionados autores, los historiadores no han vuelto a ocuparse detalladamente de esta ausencia. Los pocos que se han dedicado a examinar la influencia del Concilio de Trento en las Indias españolas se han limitado a citar y repetir sin ningunas modificaciones las observaciones y explicaciones de estos tres autores.

El objetivo de las obras respectivas de los tres padres jesuitas y, siguiendo sus comentarios, de otros historiadores era, ante todo, el de reclamar la participación directa de las iglesias de la América española en el Concilio general, y exigir cuentas de la ausencia tanto de los prelados como de los temas religiosos hispanoamericanos en Trento. Los autores mencionados, como se verá más adelante, encontraban la explicación de esta falta de representación en los impedimentos objetivos tales como la absoluta necesidad de la residencia de los obispos hispanoamericanos en sus diócesis, la enorme distancia y los peligros del viaje, en el sistema del Patronato Real dentro del cual era suficiente que los prelados presentaran al Consejo de Indias sus peticiones, y en la escasez de los conocimientos que los padres conciliares tenían sobre los asuntos hispanoamericanos.

La autora del presente ensayo, sin embargo, considera que a la luz de recientes investigaciones sobre el Concilio de Trento y, más generalmente, sobre la época de la Reforma y la Contrarreforma se puede enriquecer más la interpretación ofrecida por los autores mencionados. En las siguientes páginas, se intenta demostrar que, aunque los argumentos que presentan los padres Bayle, Leturia y Mateos tengan cierto valor y justificación, las razones de la falta de representación de los temas y de los prelados de las Indias españolas se deben buscar, ante todo, en el contexto histórico, o sea, en la coyuntura especial de aquel momento que determinó los objetivos del Concilio, en las expectativas y esperanzas que los obispos hispanoamericanos tenían en cuanto a él, y en la lógica interna del Patronato Real que iba más allá de lo planteado por los tres autores.

\section{Una pequeña revisión bibliográfica}

La época del Concilio de Trento constituye una etapa decisiva tanto para la historia moderna como para la Historia de la Iglesia. Una etapa en la que frente a los desafíos de la Reforma protestante se determinan con más claridad las posiciones del campo católico, y en la que 
gradualmente se van precisando las tendencias que serán hegemónicas dentro del catolicismo de los siglos posteriores. El Concilio de Trento cobra una importancia singular en este proceso puesto que es en su seno donde, conforme a los debates y discusiones de los teólogos y de los otros padres conciliares, se va imponiendo la victoria de unas opciones y la consiguiente exclusión de otras, cuyo resultado es que la pluralidad de interpretaciones posibles se va reduciendo en aras de una más estricta definición doctrinal, reformadora y política. El Concilio de Trento le confiere orden y figura a la Iglesia católica tanto en lo doctrinal como en lo disciplinar, en una palabra, pues, imprime orientación a toda una época histórico-eclesial. Refleja bien su singularidad el hecho de que, como se puede hablar históricamente de una Iglesia "tridentina" o "postridentina", no se puede decir lo mismo con relación a otros concilios ecuménicos ${ }^{1}$.

Como cada acontecimiento de tanta importancia, el Concilio de Trento siempre ha estado en el centro del interés tanto de los historiadores como de los teólogos. Se han producido varias obras, monografías y artículos sobre diversos puntos que van contenidos en el concepto de la historia del Concilio: su convocatoria, concurrencia, alternativas, procedimientos y resultados, o sea, todo lo referente a su posición en la historia, causas que lo motivaron, gestiones diplomáticas que le precedieron, corrientes ideológicas y vicisitudes bélicas que dejaron sentir su influencia en los debates conciliares, elementos personales que influyeron en el desenvolvimiento de la asamblea, métodos de trabajo, frutos dogmáticos y disciplinares, y su recepción y aplicación en los diferentes países ${ }^{2}$.

En este océano de obras, sin embargo, son relativamente pocos los trabajos que se dediquen a examinar la influencia de Trento en el Nuevo Mundo. Los primeros artículos, ya clásicos, publicados en los años 40 para la celebración del cuarto centenario de la inauguración del Concilio, estudiaban, en primer lugar, si había representantes de las iglesias hispanoamericanas, o si había, por lo menos, alguna mención de las Indias españolas durante las sesiones

\footnotetext{
${ }^{1}$ Klaus Schatz, Los concilios ecuménicos. Encrucijadas en la historia de la Iglesia (Valladolid: Trotta, 1999), 200.

${ }^{2}$ Véase, por ejemplo, Martín Barraza M., Valor magisterial del secreto de la justificación (sesión sexta del Concilio de Trento) (Bogotá: Pontificia Universidad Javeriana, 1959); Leon Christiani, dir., Trento (Valencia: Edicep, 1976); Jean Delumeau, El Catolicismo de Lutero a Voltaire (Barcelona: Editorial Labor, 1973); Octavio Nicolás Derisi, "La significación filosófica del Concilio de Trento y la edad moderna, 1545-1945", Colegio Mayor de Nuestra Señora del Rosario 396 (1946); Ignasi Fernández Terricabras, Felipe II y el clero secular. Aplicación del Concilio de Trento (Madrid: Sociedad Estatal para la Conmemoración de los Centenarios de Felipe II y Carlos V, 2000); Hubert Jedin, El Concilio de Trento en su última etapa. Crisis y conclusiones (Barcelona: Herder, 1965); Hubert Jedin, dir., Manual de Historia de la Iglesia, Reforma, reforma católica y contrarreforma (Barcelona: Herder, 1966), tomo V; Hubert Jedin, Historia del Concilio de Trento, tercer periodo de sesiones y conclusiones, 2 vols. (Pamplona: EUNSA, 1981); Antonio M. Navas Gutiérrez, "Trento: algunas lecciones de un gran concilio", Proyección, no. 179 (1995): 259-271; Martín Ortega Mariano, “450 años del Concilio de Trento, 1545-1563”, Religión y Cultura, no. 193 (1995): 245-279; Alfonso María Pinilla Cote, "El Concilio de Trento y la unidad religiosa", Revista Javeriana, no. 271 (1961); Schatz, Los concilios; además, la revista de la Compañía de Jesús, Razón y Fe, dedicó una edición especial al Concilio de Trento, con varios artículos sobre los temas arriba mencionados, para celebrar el cuarto centenario de su inauguración (no. 564, Tomo 131, enero de 1945).
} 
conciliares $^{3}$. Constantino Bayle se ocupó de los intentos que hubo en la América española de traer al Concilio los problemas que suscitaba la evangelización de los indios. Pedro de Leturia estudió la cuestión de por qué no concurrieron a Trento los obispos de las Indias, y, finalmente, Francisco Mateos realizó una investigación minuciosa en los gruesos tomos de las Actas del Concilio de Trento para descubrir los ecos de América, es decir, las resonancias que el descubrimiento del Nuevo Mundo y los problemas religiosos y morales relacionados con él tenían en el Concilio. Desde entonces, los historiadores no han vuelto a la problemática de la ausencia de los obispos hispanoamericanos. No obstante, los pocos que se han ocupado de la recepción y la aplicación de los decretos tridentinos en las Indias españolas, obligatoriamente han dedicado unos capítulos a los antecedentes y, entre ellos, a la representación, o más bien, a la falta de representación de las iglesias de la América española, pero no han hecho más sino repetir sin modificaciones algunas las observaciones de los tres autores mencionados ${ }^{4}$.

Los tres padres jesuitas y, siguiendo sus comentarios, otros historiadores plantean la pregunta de por qué la naciente iglesia hispanoamericana no estuvo representada en forma alguna en Trento. Parten de la convicción de que los obispos y los asuntos religiosos de estas iglesias debían estar presentes en el Concilio. Lamentan el hecho de que ni la Nueva España, ni las restantes iglesias metropolitanas de la América española estuvieron representadas, y aún más, que en las deliberaciones del Concilio resulta difícil encontrar una sola frase que se refiera directamente a los problemas específicos de tales iglesias. Nada de interesarse por la organización de las iglesias de Ultramar, nada de estudiar detenidamente y resolver las materias dogmáticas y disciplinares que eran de vital interés para la implantación y desarrollo del cristianismo en las Indias. Los tres autores detalladamente citan, como se verá más adelante, las cartas de los prelados de la América española en las que expresan su deseo de asistir al Concilio y piden la autorización del Consejo de Indias para eso. De igual manera, presentan los documentos que testifican la respuesta negativa de la Corona Española, y las diligencias que la misma efectuó ante la Santa Sede para obtener la dispensa papal de los dichos obispos. Destacan los ejemplos de los prelados hispanoamericanos que, a pesar de la prohibición real y la dispensa papal, intentaron participar personalmente en el Concilio o, por lo menos, mandar con sus procuradores las listas de los temas y las dudas que les preocupaban.

\footnotetext{
${ }^{3}$ Constantino Bayle, "El Concilio de Trento en las Indias Españolas", Razón y Fe, no. 564 (1945): 257-284; Pedro de Leturia, "Por qué la naciente iglesia hispanoamericana no estuvo representada en Trento", en Cristiani, Trento, 603615 (el artículo fue publicado por primera vez en italiano en: Il Concilio di Trento (Roma, 1942): 35-43); Francisco Mateos, "Ecos de América en Trento", en Cristiani, Trento, 565-599 (publicado por primera vez en: Revista de Indias, no. 22 (1945): 559-605.

${ }^{4}$ Véase Severo Aparicio, "Influjo de Trento en los Concilios Limenses", Missionalia Hispanica, no. 29 (1972): 215239; Reynerio Lebroc, "Proyección tridentina en América", Missionalia Hispanica, no. 77 (1969): 129-207; Francesco Leonardo Lisi, El Tercer Concilio Limense y la aculturación de los indígenas sudamericanos. Estudio crítico con edición, traducción y comentario de las actas del concilio provincial celebrado en Lima entre 1582 y 1583 (Salamanca: Gráficas Varona, 1990); Francisco Mateos, "Los dos concilios Limenses de Jerónimo de Loaysa", Missionalia Hispanica, no. 12 (1947): 479-524; Primitivo Tineo, Los Concilios Limenses en la evangelización latinoamericana. Labor organizador del Tercer Concilio Limense (Pamplona: Universidad de Navarra, 1990); Juan de Villegas, Aplicación del Concilio de Trento en Hispanoamérica, 1564-1600 (Montevideo: Instituto Teológico del Uruguay, 1975).
} 
Los tres autores afirman que la razón de que los prelados hispanoamericanos no acudieron a la asamblea religiosa hay que buscarla en impedimentos objetivos tales como la necesidad de la presencia de los obispos en los territorios recién conquistados para supervisar la tarea de la evangelización de los indios, la inmensa distancia, los peligros del viaje y la incertidumbre de la suerte del Concilio. Añaden, además, que la intervención directa de estos prelados no era necesaria por el motivo de que dentro del sistema del Patronato Real para obtener del Concilio cuanto el obispo deseaba, más que la participación personal, lo único que se requería era el presentar las propias peticiones por medio del Emperador o de sus embajadores. Como escribe Leturia,

Dentro del esquema mental del Patronato [...], la iglesia americana podía ciertamente mantener un contacto continuo con el sumo pontífice y sus órganos de acción ordinarios, pero siempre a través de su protector y patrono universal, el rey de España ${ }^{5}$.

Sin embargo, nuestros autores exigen cuentas de que en este caso por qué no se encontró presente en las sesiones conciliares, al menos algún procurador o representante de aquellas iglesias que expusiese sus progresos y sus necesidades. ¿Por qué los embajadores de Carlos V y Felipe II no proyectaron en Trento los problemas religiosos del Nuevo Mundo? Mateos, con su estilo poético, lleva más allá la pregunta:

¿Hizo algo el concilio por fomentar y organizar las iglesias que nacían detrás del océano ignoto? ¿O pretendió conscientemente inhibirse, dejando que las aguas de la fe corriesen puras por los amplios y seguros cauces del patronato de los monarcas de España y Portugal? ¿Sintió el concilio que su misión debía ceñirse a combatir el protestantismo en Europa? .

Los tres autores unánimemente asientan que las cuestiones que se debatían en Trento eran enteramente europeas. Afirman que el Concilio se hallaba a la vista, ante todo, del protestantismo; ese era el problema principal que, por encima de cualquier otro, preocupaba a los padres y teólogos congregados allí. Argumentan que este desinterés por los temas religiosos de la América española se puede explicar, ante todo, por la escasez e imprecisión de los conocimientos que los padres conciliares y los altos funcionarios de la Curia Romana tenían de los asuntos hispanoamericanos. Aunque ellos seguían con interés las cosas singulares y extraordinarias que de ella contaban, no poseían informaciones precisas sobre la situación imperante en las Indias españolas para tomar decisiones sobre los problemas especiales que habían surgido de la experiencia evangelizadora en los territorios recién conquistados.

América aún estaba muy lejos del pensamiento universal, [...] no había aún llegado a influir de modo importante en el interés y la vida del mundo cristiano?

\footnotetext{
${ }^{5}$ Leturia, "Por qué la naciente iglesia", 606.

${ }^{6}$ Mateos, "Ecos de América", 566, 592.

${ }^{7}$ Mateos, "Ecos de América", 565.
} 
En resumen, los padres Bayle, Leturia y Mateos eran los primeros en plantear el problema de la representación de los obispos y de los temas hispanoamericanos en el Concilio de Trento. Ellos eran los primeros en detectar y enumerar aún las menores alusiones que se hallaran en las gruesas actas del Concilio y, sobre todo, en localizar y publicar los documentos, cartas y constancias referentes al asunto que se hallaran en los archivos españoles y romanos. Gracias a su trabajo minucioso se conoció por primera vez la correspondencia entre los obispos hispanoamericanos y el Consejo de Indias, entre la Corona Española y la Santa Sede sobre la participación de los prelados de las Indias españolas en el Concilio general, y se aclaró que estas iglesias no estuvieron representadas en ninguna forma. Nuestros autores, entonces, partiendo de la suposición de que tanto los obispos como los temas hispanoamericanos debían estar presentes, exigían cuentas de la razón de esta ausencia. Como se vio, la explicación de esta falta de representación la encontraban en los impedimentos objetivos, en el sistema del Patronato Real y en la escasez de los conocimientos que los padres conciliares tenían sobre los asuntos hispanoamericanos.

Desde entonces, los historiadores no han vuelto a ocuparse de la problemática. Los pocos que se han dedicado a investigar la recepción y aplicación de los decretos tridentinos en la América española, en su mayoría autores relacionados con la Iglesia, se han conformado con citar y repetir sin modificaciones algunas las observaciones y explicaciones de los tres autores clásicos, tal vez porque pensaban que, sin presentar nuevas fuentes documentales sobre el asunto, no se podían dar nuevos aportes para interpretar de diferente manera la ausencia de los representantes de las iglesias hispanoamericanas en Trento.

La autora del presente ensayo, sin embargo, considera que sí vale la pena volver a estudiar el problema de esta ausencia puesto que, a la luz de recientes investigaciones sobre el Concilio de Trento y, más generalmente, sobre la época de la Reforma y la Contrarreforma, se puede explorar la cuestión desde otras perspectivas y se puede enriquecer mucho más la interpretación ofrecida por los autores mencionados. Eso no significa que sus argumentos y explicaciones no tengan valor y justificación, pero se cree que, para determinar las razones de la falta de representación de las iglesias hispanoamericanas, hay que tener en cuenta varios factores de carácter mucho más general de lo que plantearon los padres Bayle, Leturia y Mateos.

\section{2. "Tomamos también la resolución de convocar un concilio ecuménico"}

\subsection{Antecedentes}

Ya desde el siglo XIV venía advirtiéndose en la Iglesia la necesidad de una reforma in capite et in membris, es decir, se iba imponiendo la convicción de que cualquier reforma de la Iglesia que quisiera ser eficaz había de empezar desde arriba, desde la cabeza, o sea, desde el Papa y la 
Curia Romana ${ }^{8}$. En este sentido se expresaban ya los concilios ecuménicos de la época (Vienne 1311-12, Constanza 1414-18, Basilea-Ferrara-Florencia 1431-47, Letrán V 1512-17), los distintos programas de reforma, situados dentro y fuera de la jerarquía eclesiástica, y gran número de documentos contemporáneos ${ }^{9}$. Sin embargo, no era una tarea fácil realizar esta idea de reforma. Los abusos, tales como la vulneración de la residencia obligatoria, la acumulación de beneficios, los escasos conocimientos y la vida poco ejemplar de los párrocos, la simonía o el nepotismo, objeto de lamentación en todos los círculos sensibles a la reforma, estaban tan profundamente arraigados en las estructuras político-sociales que hacían fracasar todo intento renovador.

La Reforma protestante llegó a revelar en toda su amplitud la profundidad de esta crisis de la vida religiosa y la necesidad de responder a las exigencias del cambio. También el avance rápido del protestantismo y el alejamiento en masa de la Iglesia Romana exigían una solución urgente y eficaz. Tradicionalmente, la convocatoria de un concilio es el último recurso de que la Iglesia se vale para afrontar un momento crítico, oponerse a las herejías en expansión o vencer las resistencias más tenaces a la reforma. Así no es de sorprender que la idea de celebrar un concilio ecuménico haya tomado cuerpo muy temprano, ya en la década de 1530 , tanto en los círculos eclesiásticos como en los seculares. A pesar de los fracasos de los intentos anteriores, para los hombres de aquella época, el concilio seguía siendo el único medio para ayudar a la Iglesia, sanar la crisis y lograr salvar la unidad de la cristiandad.

Sin embargo, transcurrió mucho tiempo hasta que un concilio general llegó a reunirse puesto que la convocatoria se encontraba con diversos obstáculos e impedimentos en el terreno político. Por su parte, el Emperador Carlos V con todas sus fuerzas apoyó la convocatoria puesto que necesitaba el concilio para su política de apaciguamiento frente a los estamentos imperiales, implicados en la Reforma. Sus expectativas y planes, no obstante, chocaban con la oposición definida del Papa Clemente VII (1523-34) y del rey de Francia, Francisco I (151547). Por un lado, el miedo del Papa hacia un concilio era aún mayor que el temor ante la revolución eclesial en Alemania. Su estrategia, por consiguiente, consistía en practicar

\footnotetext{
${ }^{8}$ La bibliografía especializada utiliza la expresión Reforma Católica para denominar a este movimiento católico de reforma. El concepto se refiere, frente a la Reforma protestante, a la reflexión que la Iglesia hace sobre sí misma, de cara a la renovación interna de la vida católica. Hay autores que utilizan este concepto como sinónimo de la Contrarreforma (p. ej. Fernández, Felipe II, 22); otros, especialmente los historiadores católicos, lo emplean para abandonar definitivamente el de Contrarreforma, puesto que, según ellos, este parece entender el fortalecimiento de la Iglesia Católica unilateralmente como reacción contra la escisión de la fe y está relacionado con el empleo de la violencia en materia religiosa (p. ej. Cristiani, Trento, 264-265). El presente ensayo, sin embargo, sigue la posición que aboga por mantener ambos conceptos: Contrarreforma para designar las manifestaciones resueltamente antiprotestantes del Catolicismo en vía de renovación, de los siglos XVI y XVII; y Reforma Católica en el sentido arriba descrito. Según esta posición, ambos conceptos poseen su justificación pero no designan movimientos tajantemente separados, sino conectados entre sí. Jean Delumeau, La reforma (Barcelona: Editorial Labor, 1977), V; Jedin, Manual de Historia, 591-594; Guido Zagheni, Curso de Historia de la Iglesia, La Edad Moderna (Madrid: San Pablo, 1997), 3:35-36.

${ }^{9}$ El presente trabajo no tiene el objetivo de ocuparse de los intentos de reforma anteriores al Concilio de Trento. Para mayor información véase, por ejemplo, la excelente síntesis en: Schatz, Los concilios. Véase además Delumeau, El Catolicismo de Lutero; Delumeau, La reforma; Jedin, Manual de Historia; Zagheni, Curso de Historia.
} 
permanentemente una política obstruccionista para la cual la interminable guerra entre Francia y los Habsburgo constituía un pretexto oportuno. Por el otro, Francia se sentía rodeada y amenazada en razón de la aglomeración de países controlados por Carlos V. Francisco I consideraba que la Reforma protestante le favorecía puesto que tenía ocupado al Emperador en Alemania, debilitando así su posición. Por lo tanto, nunca aceptó enviar representantes al concilio $^{10}$.

\subsection{EI Concilio de Trento}

Con el pontificado de Paulo III (1534-49) se produjo un tímido cambio de rumbo en la Curia Romana. A comienzos del año 1536, el Papa prometió al Emperador la convocatoria del concilio. Conforme a esta promesa, la primera convocatoria se realizó el 2 de junio de 1536 para Mantua, donde el concilio debía comenzar su trabajo en mayo del año siguiente. Sin embargo, las exigencias del duque de Mantua, que reclamaba un fuerte ejército para la tutela de la asamblea, impusieron la elección de otra sede, Vicenza, en territorio veneciano, y el aplazamiento del concilio a 1538. Pero en esta nueva fecha, debido a la guerra en curso, fueron pocos los prelados que pudieron llegar a la ciudad designada. Así la inauguración oficial se fue retrasando de una fecha a otra, y, finalmente, el concilio quedó aplazado, a comienzos de 1539, por un tiempo indeterminado.

Se eligió entonces una nueva sede, a saber, la ciudad de Trento, cosa que resultó aceptable para todos los interesados. La ciudad estaba situada dentro del Imperio, aunque no formaba parte de los territorios de los Habsburgo, y, al mismo tiempo, era muy accesible a los obispos italianos. Así, en 1542 se hizo una nueva convocatoria, pero inmediatamente hubo de ser aplazada puesto que justo en este momento estalló un nuevo conflicto bélico entre Francia y el Emperador. En septiembre de 1544, Carlos V y el rey de Francia, por fin, habían firmado un acuerdo (paz de Crépy) que hizo posible la nueva convocatoria para la fecha del 25 de marzo de 1545 . Como apenas aparecieron algunos, la inauguración fue nuevamente aplazada. El Concilio de Trento, por fin, se inauguró solemnemente el 13 de diciembre de 1545 contando con la presencia de 31 padres conciliares.

El primer problema que había de resolver era el de la temática conciliar detrás del cual se escondían expectativas diversas. La idea del Emperador reposaba sobre la intención de dar lugar a un concilio de unión, por lo tanto, según él, desde el punto de vista de la temática, el concilio tenía que ser de reforma. Sólo una de estas características podía esperar credibilidad entre los protestantes y podía frenar la Reforma puesto que los abusos en la disciplina eran uno de los motivos más importantes del movimiento protestante. Además, la determinación definitiva de las cuestiones dogmáticas podía alejar más a los protestantes: como ellos se negaron a someterse al Concilio de Trento y no enviaron sus representantes, mientras no se consiguiera su

\footnotetext{
${ }^{10}$ Schatz, Los concilios, 158-159.
} 
derrota militar para poder obligarles a sentarse a la mesa, no debían adoptarse decisiones doctrinales previas que cerraran para siempre las puertas del diálogo. En cambio, como las cuestiones de reforma disciplinarias tocaban muy directamente a los eclesiásticos, a los cardenales y al Papa, la Curia Romana insistía más en la necesidad de acabar de una vez las discusiones sobre los puntos más controvertidos del dogma. Así, para ella, tenía más prioridad la definición clara de la doctrina católica en los puntos atacados por los protestantes ${ }^{11}$. En fin, en la alternativa entre concilio doctrinal o concilio de reforma se llegó al acuerdo de que debía cumplir con ambos propósitos. El método de trabajo, por lo tanto, fue el de intercalar decretos dogmáticos y disciplinarios o de reformatione sobre las más diversas materias. Hay que añadir, no obstante, que, mientras que se determinaban cuestiones dogmáticas tan cardinales como el pecado original, la justificación o los sacramentos, las reformas radicales de naturaleza estructural, tal y como reclamaban los obispos españoles, fracasaban por la oposición decidida del partido papal.

Sin embargo, resuelto este problema cardinal, el Concilio no pudo trabajar tranquilamente por mucho tiempo. En 1547, tras la comprobación de algunos casos aislados de tifus, los delegados papales, en virtud de los plenos poderes otorgados por Paulo III, hicieron la propuesta de trasladar el concilio a Bolonia, en los Estados pontificios. El Concilio dio su aprobación, aunque una minoría de padres, en su mayoría españoles, presentó su objeción. Este traslado a Bolonia provocó el conflicto entre el Papa y el Emperador, y el Concilio quedó en suspenso por tiempo indefinido ${ }^{12}$.

Sólo la elección del nuevo Papa, Julio III (1550-1555) permitió retomar el Concilio en 1551. En este período (1551-52) el Emperador consiguió que los estamentos protestantes del Imperio se comprometieran a enviar representantes a la asamblea. Sin embargo, tampoco en esta ocasión le salieron las cuentas a Carlos V. La alianza de los protestantes con el rey francés y su avance militar sobre los Alpes obligó a los delegados a suspender de nuevo el Concilio el 28 de abril de 1552.

Tras el breve pontificado de Marcelo II (1555) se eligió un pontífice sinceramente comprometido con la reforma. Sin embargo, Paulo IV (1555-1559) se negó a convocar el Concilio. Su ideal era llevar a cabo la reforma, pero una reforma dirigida y desarrollada desde

\footnotetext{
${ }^{11}$ Bernardino Llorca, "La reforma disciplinar de la Iglesia y el Concilio de Trento", Razón y Fe, no. 564 (1945): 99$115,103$.

${ }^{12}$ Como afirma Schatz, probablemente la razón real de este traslado era el miedo de los padres conciliares al poderío imperial que, tras la victoria decisiva de Carlos V contra la Liga de Esmalcalda en Mühlberg, parecía todavía más inminente, y también el deseo de estar más libre de este poderío en una ciudad de los Estados de la Iglesia. Los delegados temían, además, que, si los protestantes vinieran al Concilio por obligación de Carlos $\mathrm{V}$, correría peligro lo que habían conseguido hasta entonces en materias dogmáticas. Schatz, Los concilios, 180. Véase Bula para poder transferir el concilio, Concilio de Trento, Sesión VII, en El Sacrosanto y ecuménico Concilio de Trento, traducido al idioma castellano por Ignacio López de Ayala. Agregase el texto original corregido según la edición auténtica de Roma, publicada en 1564 (Madrid, 1785), 107-111; Decreto sobre la traslación del concilio, Sesión VIII, en El Sacrosanto, 111-113; lista de los prelados que protestaron la traslación del Concilio a Bolonia, Apéndice V, en $E l$ Sacrosanto, XL.
} 
Roma. Sus tentativas reformadoras, no obstante, fracasaron, puesto que ni los oficiales de la Curia ni los grupos reformistas confiaban en la perdurabilidad de una reforma guiada desde Roma. Tras su fracaso, todas las esperanzas se depositaban de nuevo en el Concilio. La nueva convocatoria y la tercera etapa del Concilio de Trento se realizaron durante el pontificado de Pío IV (1559-1565). El Concilio se reanudó el 18 de enero de 1562 y se clausuró con la sesión XXVI, el 4 de diciembre de $1563^{13}$.

\subsection{Marco histórico de la tercera etapa}

Antes de la convocatoria del Concilio quedaba pendiente una importante decisión previa, a saber, decidir cómo considerarlo; si como la prolongación del anterior, o como uno nuevo sin continuidad con el anterior. De fondo se encontraba nuevamente la pregunta acerca de si se debía acometer un último intento para superar la división confesional, o si debía aceptarse como un hecho consumado y dedicarse a consolidar al resto católico. Para aquellos que todavía tenían la esperanza de lograr salvar la unidad de la cristiandad era indispensable considerar como no existentes los decretos tomados hasta ese momento, en especial los de cuestiones dogmáticas, y disponerse a abrir nuevas negociaciones con los delegados protestantes. En otro caso se podía aceptar la continuidad del Concilio y, de esa manera, la vigencia de las decisiones ya conseguidas $^{14}$.

Sin embargo, al reiniciar el Concilio, a comienzos de 1562, la situación había cambiado mucho en diversas perspectivas respecto a la primera fase. Ya no existía, tras la abdicación de Carlos $\mathrm{V}$ (1556), la unidad del Imperio y España. En los territorios imperiales regía Fernando I, en España y en los territorios coaligados el rey Felipe II. El protestantismo había hecho avances ulteriores: Francia estaba amenazada; Inglaterra se perdió definitivamente tras el fracaso del intento de restauración católica de la reina María (1553-1558). En Alemania la paz religiosa de Augsburgo (1555) había legalizado el protestantismo a nivel imperial, en la medida en que se confiaba a los príncipes la decisión sobre la confesión en su territorio (el principio de cuius regio, eius religio). Se llegó, por fin, tras largos años de guerras, a una delicada paz, que nadie quería romper, y que sancionaba jurídicamente la definitiva división de la cristiandad.

En estas condiciones, el compromiso asumido por Pío IV de convocar el Concilio no podía tener el mismo sentido que en la década de 1540. En la última etapa del Concilio de Trento (1562-63), entonces, ya no se pensaba en restablecer un nuevo diálogo con los protestantes para restablecer la unidad religiosa, sino en mantener una fórmula de coexistencia de las diferentes confesiones. Ya no se trataba de armonizar los cultos, sino de detener el avance protestante, de conservar en su fe a los que se habían mantenido irreductiblemente católicos en el período de mayores turbulencias religiosas, y de proveerse de las armas necesarias, a saber, la clarificación del cuerpo doctrinal católico en oposición al protestante y la reforma disciplinar de toda la organización eclesiástica ${ }^{15}$.

\footnotetext{
${ }^{13}$ Fernández, Felipe II, 33-34.

${ }^{14}$ Schatz, Los concilios, 186.

${ }^{15}$ Schatz, Los concilios, 185; Fernández, Felipe II, 34-42.
} 


\subsection{Confirmación y aceptación de los decretos}

En el consistorio decreto del 26 de enero de 1564, Pío IV confirmó solemnemente los decretos del Concilio de Trento con una fórmula que daba por válido lo aprobado en sus tres etapas. Sin embargo, la bula Benedictus Deus no fue publicada hasta el 30 de junio del mismo año, 5 meses más tarde, aunque antedatada a la fecha de la confirmación verbal. Fernández Terricabras afirma que esta dilación era fruto de las fuertes discrepancias entre los diversos grupos que querían obtener una redacción de la confirmación escrita favorable a sus intereses ${ }^{16}$. El problema planteado en torno a la confirmación papal del Concilio de Trento no era una simple discusión protocolaria. Era, ante todo, una cuestión de control que remitía a un punto fundamental, a saber, a decidir a quién incumbiría la ejecución del Concilio, al Papa o a los príncipes. Lo que estaba en juego era determinar quién ejercería el papel de garante del Concilio en el nuevo panorama eclesiástico $\mathrm{y}$, por lo tanto, quién podría encargarse de que éste se aplicara según sus propios criterios. En última instancia, pues, la cuestión iba dirigida a determinar quién debería asumir el liderazgo de la reforma tridentina.

El Papa quería dejar a salvo su libertad de interpretar, ejecutar o dispensar el Concilio, aun después de haberlo confirmado. Su objetivo era poder garantizar el predominio de sus criterios en la evolución religiosa, y poder establecer definitivamente una concepción operativa y no meramente simbólica de la primacía del obispo de Roma. Para los poderes seculares, por el contrario, la confirmación papal del Concilio y sus consecuencias constituían un medio para legitimar la injerencia de Roma en los asuntos de sus estados. Además, según ellos, era conveniente que el soberano participara activamente en la aplicación de los decretos, precisamente para impedir que la Santa Sede pudiera diluir el Concilio con sus declaraciones, interpretaciones y modificaciones.

La bula Benedictus Deus, publicada el 30 de junio de 1564, en efecto, no se limitaba a transcribir la confirmación verbal, sino que añadía dos importantes prohibiciones. La primera era que nadie podía publicar comentarios o anotaciones al Concilio sin la autorización del Papa. La segunda era que la única instancia capacitada para resolver cualquier duda sobre los decretos era la Santa Sede. Con esto, Pío IV, en primer lugar, garantizaba la potestad papal de interpretación y dispensa y, en segundo, impedía que los teólogos y políticos de otros reinos pudieran elaborar publicaciones e interpretaciones propias. Sin embargo, los poderes seculares veían con mucho recelo tanto ciertos decretos tridentinos como la pretensión hegemónica papal. Por lo tanto, muy pronto se planteaban en muchos reinos europeos disputas por la interpretación y la ejecución del Concilio de Trento, aunque quizás de forma más sutil en la Monarquía Hispana. En teoría, Felipe II, con la pragmática del 12 de julio de 1564, aceptó íntegramente el Concilio; en la práctica, sin embargo, se desplegó una acción política que alternaba el apoyo

\footnotetext{
${ }^{16}$ Fernández, Felipe II, 104-110.
} 
decidido a la reforma tridentina en muchos aspectos con la reticencia, cuando no la franca negativa, a la ejecución de ciertos decretos ${ }^{17}$.

\section{3. "Paz y unión de la iglesia"}

Benedict Anderson (1993) describe las grandes culturas religiosas, y entre ellas la cristiandad, como inmensas comunidades sagradas que abarcan vastos territorios y que, por lo tanto, sólo son imaginables por medio de una lengua sagrada y de conceptos compartidos por todos los miembros de esa comunidad. Aunque las lenguas sagradas hicieran imaginables una comunidad como la cristiana, el ámbito real y la verosimilitud de estas comunidades no pueden explicarse sólo por la escritura sagrada: después de todo, sus lectores eran pequeños enclaves de gente alfabetizada entre grandes multitudes iletradas. Los letrados, principalmente eclesiásticos, en este contexto, eran estratos estratégicos de una jerarquía cosmológica cuya cúspide era divina.

El asombroso poder del papado en su apogeo sólo puede comprenderse en términos de un clero transeuropeo que escribía en latín, y una concepción del mundo, compartida virtualmente por todos, en el sentido de que la intelligentsia bilingüe, al mediar entre la lengua vernácula y el latín, mediaba entre la tierra y el cielo ${ }^{18}$.

En el mundo cristiano occidental convivían conceptos, principios, valores e imágenes que durante siglos la comunidad cristiana había construido para sí y sobre sí misma. Aunque diferentes movimientos situados dentro y fuera de la jerarquía eclesiástica reclamaban ya desde el siglo XIV algunos cambios y reformas, en especial, la depuración de la Iglesia y de las costumbres de sus ministros, la coherencia misma de esa comunidad no estuvo atacada seriamente. Sin embargo, la llegada de Martín Lutero y el movimiento protestante cambió profundamente la situación. Sus críticas agudas a la Iglesia y su interpretación diferente del contenido conceptual del cristianismo y de las expresiones formales que lo manifestaban, a pesar de los intentos de llegar a algún tipo de compromiso, impidieron cualquier reconciliación entre la Iglesia Romana y los protestantes. En consecuencia, la coherencia de la comunidad

\footnotetext{
${ }^{17}$ Sobre la política de Felipe II en torno a la aceptación y la aplicación de los decretos tridentinos en la Península, véase el excelente trabajo de Ignasi Fernández Terricabras (Felipe II y el clero secular). Sobre la aceptación del Concilio en otros reinos de Europa, véase Jedin, Manual de Historia de la Iglesia, y una pequeña síntesis en Fernández Terricabras, Felipe II y el clero secular. Sobre la aplicación de Trento en la América española, véase Aparicio, "Influjo de Trento"; Lebroc, "Proyección tridentina en América"; Lisi, El Tercer Concilio Limense; Mateos, "Los dos concilios Limenses"; Tineo, Los Concilios Limenses; Villegas, Aplicación del Concilio de Trento. Hay que añadir que estas obras se dedican casi exclusivamente al estudio de la provincia eclesiástica del Perú, con excepción de Reynerio Lebroc quien se ocupa de México. Sobre la influencia tridentina en el Nuevo Reino de Granada no existen trabajos ni recientes ni detallados: véase José Manuel Groot, Historia eclesiástica y civil de Nueva Granada, 5 vols. (Bogotá: A. B. C., 1953); Carlos E. Mesa, Concilios y sínodos en el Nuevo Reino de Granada, hoy Colombia (Madrid: Raycar, 1974); José Restrepo Posada, "La evangelización del Nuevo Reino (siglo XVI)", Historia Extensa de Colombia (Bogotá: Lerner, 1971), 13:1.

${ }^{18}$ Benedict Anderson, Comunidades imaginadas: reflexiones sobre el origen y la difusión del nacionalismo (México: Fondo de Cultura Económica, 1993), 35.
} 
sagrada del cristianismo occidental se rompió y se estableció una división definitiva entre protestantes y católicos.

Es ese contexto en el cual se puede entender mejor la importancia del Concilio de Trento. En un primer momento, el Concilio se convocó con la esperanza de que "se podría restablecer con él la paz del pueblo cristiano, y la unidad de la religión de Jesu Cristo"19. Cuando en diciembre de 1545 se juntaron los padres conciliares en la sesión de apertura, todos dieron su placet al decreto que declaraba haberse comenzado el Concilio general,

(...) para aumento y exaltación de la fe y religión cristiana, extirpación de las heregías, paz y concordia de la Iglesia, reforma del clero y pueblo cristiano, y humillación, y total ruina de los enemigos del nombre de Cristo" ${ }^{20}$.

En la Bula de restauración del Concilio, con fecha de 14 de noviembre de 1550, se resaltaba de nuevo que el objetivo de la asamblea era "disipar las disensiones que sobre materias de nuestra Religión han subsistido vigorosamente por largo tiempo en la Alemania" ${ }^{21}$.

Las dos primeras etapas conciliares, pues, miraban ante todo a Alemania, lugar de origen de la crisis religiosa, y estaban dominadas por el problema de reconciliación entre católicos y protestantes. Sin embargo, muy pronto se puso de manifiesto que la idea de los protestantes de concilio (que debía ser "libre y cristiano") y la concepción papal de lo mismo no eran reconciliables. Los protestantes no estaban dispuestos a someterse a un concilio como el reunido en Trento, y no participaron en la primera etapa. En el segundo período, obligados por el Emperador Carlos V, ya asistían sus representantes pero exigían un nuevo debate de las resoluciones ya adoptadas, o sea, reclamaban que todo se discutiera nuevamente sobre el único presupuesto de la Sagrada Escritura. Por su parte, la Curia Romana tampoco estaba dispuesta a hacer concesiones. De esta manera, la intransigencia de ambos lados impidió que el Concilio pudiera alcanzar su objetivo principal, a saber, salvar la paz y unión de la Iglesia. Con estas diferencias profundas, el margen de negociación, o siquiera de diálogo, era nulo, y el Concilio sólo servía para condenar "la herejía protestante".

En la tercera etapa, como quedó aclarado, tras conseguir una delicada paz con los protestantes, la Iglesia Romana tenía que aceptar el hecho de la división irreversible de la comunidad sagrada del cristianismo y redefinirse, ahora ya, como la comunidad católica. Aceptando los decretos aprobados y continuando con el trabajo comenzado en los dos períodos anteriores, se aclaró por vez primera cuál era la doctrina católica: el Concilio definió y delimitó los dogmas y verdades de la fe católica frente a los principios protestantes, y sancionó un programa de reforma destinado a eliminar a los abusos más graves de la Iglesia.

\footnotetext{
${ }^{19}$ Bula de convocatoria del 22 de mayo de 1542, en El Sacrosanto, XXIII-XXIV.

${ }^{20}$ Concilio de Trento, Sesión I, El Sacrosanto, 1-2.

${ }^{21}$ El Sacrosanto, 118-119.
} 
Todas las medidas tomadas estaban encaminadas a producir una nueva imagen de la Iglesia Romana y reforzar una nueva unidad de la comunidad sagrada. Para tal efecto los decretos y los documentos relacionados, tal como era el Catecismo romano (1566), el Breviario (1568) y el Misal (1570), no solamente determinaron los cánones y dogmas de la fe católica que todos los creyentes tenían que creer y confesar, sino unificaron y uniformizaron todos los momentos de la vida religiosa, desde la forma de celebrar la misa y de administrar los sacramentos, a través de los vestidos y comportamientos tanto de los fieles como de sus pastores, hasta las expresiones formales de la religión. El hecho de mantener la lengua latina en la liturgia, es decir, el no conceder a los laicos ni la Biblia ni la misa en lengua vernácula muestra lo importante que era para los padres conciliares rescatar la lengua sagrada de la comunidad y así resaltar y reforzar la importancia de la Iglesia y de sus sacerdotes como mediadores entre el latín y las lenguas vernáculas, entre Dios y los fieles ${ }^{22}$. En última instancia, pues, Trento, redefiniendo los conceptos del catolicismo y sus representaciones visuales y auditivas, contribuyó a reconstruir la comunidad sagrada, o sea, a crear una nueva realidad, imaginada por los padres conciliares, pero vigente para todos los miembros de la comunidad católica.

Como se puede ver, el Concilio de Trento en ninguna de sus tres etapas pudo ser el concilio que los padres Leturia, Mateos y Bayle reclamaban en sus respectivos artículos. En el momento histórico dado la Iglesia Romana tuvo que decidirse a reaccionar ante los retos planteados por Lutero ya hacía 25 años antes. Hasta entonces la Reforma protestante prosiguió su expansión ante un catolicismo desorientado, lento e indeciso, que todavía no había sabido dotarse de los recursos teológicos y disciplinarios para hacerle frente. El Concilio de Trento venía, pues, precisamente para resolver este problema, es decir, para afrontar este momento crítico y brindar soluciones para sanar la crisis. Por lo tanto, no pudo tener presente otros problemas sino los europeos.

\section{4. "Nos desearíamos estar presente"}

\subsection{Prohibición real y dispensa papal}

En el momento en el que perdió terreno en Europa frente al protestantismo, la Iglesia Romana estaba acrecentándose con la agregación de nuevos pueblos en las Indias. Cuando el Papa Paulo III anunció en 1536 la celebración de un concilio ecuménico para Mantua, existían en las Indias españolas 14 obispados. Al inaugurarse la primera sesión del Concilio de Trento, el 13 de diciembre de 1545, ya había 17 obispados. El 11 de febrero de 1546, por súplicas del rey español, el Papa separó estas diócesis de la iglesia madre de Sevilla, elevó a México a la

\footnotetext{
${ }^{22}$ Klaus Schatz afirma que entre los padres conciliares era muy común la opinión de que, como el enfermo no necesita conocer la composición de su medicina, al pueblo también le "basta saber que el sacerdote intercede por él ante Dios; entender el tenor de sus palabras no es para el pueblo más importante que para el acusado comprender el tenor del alegado de su defensor". Schatz, Los concilios, 195.
} 
categoría de metropolitana de 5 diócesis ${ }^{23}$, al mismo tiempo que erigió en provincia eclesiástica, bajo el arzobispado de Santo Domingo, las 6 sedes episcopales de las Antillas, de Venezuela y del Nuevo Reino de Granada ${ }^{24}$, y, por último, a la sede metropolitana de Lima sometió los 5 obispados existentes en América Central y en el antiguo imperio de los incas ${ }^{25}$. De esta forma, durante las primeras sesiones tridentinas ya existían en las Indias españolas tres arzobispados con sus respectivas sedes metropolitanas y 16 obispados $^{26}$.

Las bulas de convocatoria del concilio general les llegaron a los obispos de las iglesias de las Indias españolas también. Como los otros patriarcas, arzobispos y obispos del mundo cristiano, ellos también debían asistir personalmente o, en el caso de grave impedimento, por medio de sus legítimos procuradores. Los obispos hispanoamericanos, por lo tanto, se sintieron llamados y deseosos de acudir a la asamblea religiosa. El obispo de México, Juan de Zumárraga, manifestó claramente este deseo cuando, al recibir la citación para Mantua en 1536, escribió así al Consejo de Indias:

Nos desearíamos estar presente, no obstante los peligros del camino y la gran distancia que nos separa; mas el señor don Antonio de Mendoza, virrey de las Indias y gobernador de toda la Nueva España, ha estimado [...] que no debemos movernos de estas partes, por el daño que nuestra ausencia de esta tierra puede causar, no solo a los nuevamente convertidos, sino a los españoles ${ }^{27}$.

En noviembre de 1537, los obispos de la Nueva España celebraron en la capital del Virreinato una reunión eclesiástica que trató varias cuestiones referentes a la organización de estas iglesias. Una de estas cuestiones fue la conveniencia de intervenir directamente en el concilio general. En su carta colectiva al Emperador, el 30 de noviembre de 1537, los obispos de México, Guatemala y Oaxaca repetían de nuevo la petición de asistir al Concilio:

Suplicamos a V. M. nos haga merced de nos mandar enviar la instrucción y manera que debemos tener en la ida al concilio general [...], porque nosotros estamos muy

\footnotetext{
${ }^{23}$ En la bibliografía especializada existe una enorme confusión acerca del número y de los nombres de los obispados hispanoamericanos de esta época. Para la siguiente lista véanse las tablas en: Enrique Dussel, dir., Historia General de la Iglesia en América Latina, Tomo I/1, Introducción general (CEHILA: Ediciones Sígueme, 1983), 420-423, y Juan Marchena Fernández, La jerarquía de la Iglesia en Indias: el episcopado americano, 1500-1850 (Madrid: MAPFRE, 1992), 156-163. Las diócesis que pertenecían al arzobispado de México eran: Tlaxcala, Oaxaca, Michoacán, Chiapas y Guatemala.

${ }^{24}$ San Juan de Puerto Rico, Cuba, Coro (Venezuela), Trujillo de Comayagua (Honduras), Santa Marta y Cartagena de Indias (Colombia).

${ }^{25}$ Nicaragua, Panamá, Cuzco, Quito y Popayán (Colombia).

${ }^{26}$ Cuando se reabrió el Concilio en su período final, en 1562, ya se habían creado 6 nuevas jurisdicciones episcopales: Asunción (Paraguay), Guadalajara, La Plata (Charcas), Santiago de Chile, Yucatán y La Imperial (Chile).

${ }^{27}$ Citado en Bayle, "El Concilio", 258-259; Tineo, Los Concilios Limenses, 144.
} 
aparejados, aunque más distantes estemos, de ir a cumplir lo que los sagrados cánones nos mandan ${ }^{28}$.

Los obispos urgían, pues, una decisión definitiva por parte de la Corona acerca de su participación, sin embargo, acentuaban que, para no acudir al Concilio, se requería imprescindiblemente la autorización del Sumo Pontífice también:

[...] si fuese servido de nos mandar quedar a todos o parte de nos, tenga por bien mandar a su embajador cómo nos manda quedar, para que haga de su Santidad licencia para ello, y nos la manda enviar ${ }^{29}$.

El asunto había sido discutido en varias ocasiones en el Consejo de Indias y como resultado de estas deliberaciones se redactaron varios despachos. A principios de 1538, se escribió al virrey de Nueva España una carta que quedó registrada en el Consejo en estos términos: "El virrey de Nueva España no deje salir los prelados de tierra por ser acabado el concilio y por otras causas" ${ }^{\prime 30}$. Poco después, el 23 de agosto de 1538, también se envió la respuesta a los obispos de la Nueva España:

En lo que toca a vuestra ida al Concilio, éste se ha alargado por algunos días, y ansí por esto como por otras causas, ha parecido que no debeis ir a él ninguno de vosotros $^{31}$.

Las razones de esta ausencia, decretado por el Consejo de Indias, quedaron apuntadas en la carta que, en ausencia de Carlos V, la reina Isabel había escrito unos meses antes al embajador de España ante la Santa Sede, dándole instrucciones para que solicitara del Papa la dispensa de los obispos hispanoamericanos de la asistencia al Concilio y explicara los motivos de tal petición. Estas razones, pues, en las que se apoyó la solicitud, como ya vimos en los documentos anteriores también, eran la absoluta necesidad de la residencia de los obispos en sus diócesis para el bien tanto de los recién convertidos como de los españoles, y la enorme distancia:

Ya sabeis lo que nuestro muy Santo Padre Paulo Tercio ha ordenado y mandado cerca del Concilio que se ha de hacer y celebrar. Y porque, como sabeis, para ello se han llamado todos los prelados de nuestros reinos, y entre ellos a los que residen en las nuestras Indias del Mar Océano; y al mismo tiempo que el emperador, mi

\footnotetext{
${ }^{28}$ Citado en Bayle, "El Concilio", 259; Leturia, "Por qué”, 608; Mesa, Concilios y sínodos, 7; Tineo, Los Concilios Limenses, 144-145.

${ }^{29}$ Ibídem.

${ }^{30}$ Citado en Bayle, "El Concilio ", 260; Leturia, "Por qué", 608; Tineo, Los Concilios Limenses, 145. Parece que esta situación se aprovechó por parte de la Corona para una orden de carácter más general que prohibía a los obispos de Indias venir a España sin licencia del Rey. Esta orden más tarde pasó al código de las Leyes de Indias bajo el título de "Prelados no se vengan de las Indias a estos reinos ni a otra parte sin licencia de su majestad, ni las justicias los dejen venir" (Recopilación de Leyes de los reinos de las Indias, Libro I, Título 7, Ley 36).

${ }^{31}$ Citado en Bayle, "El Concilio", 260; Leturia, "Por qué", 609; Mesa, Concilios y sinodos, 7; Tineo, Los Concilios Limenses, 145.
} 
señor, los mandó presentar a Su Santidad para obispos de aquellas iglesias fue la intención que residiesen en ellas y entendiesen en la instrucción de los indios naturales de aquellas partes en las cosas de nuestra santa fe; y si se ausentasen de los dichos sus obispados los dichos indios no serían tan bien instruidos, como convenía, ni se podría conseguir el fruto que deseamos, de que Dios Nuestro Señor sería deservido, y así por esto como por la distancia que hay de las dichas Indias a esas partes. Luego que éstas recibais hablad a Su Santidad para que conceda Breve por el cual haya por excusados los dichos prelados y les dé licencia para que no vengan al dicho Concilio ${ }^{32}$.

Aunque no se conoce la respuesta del Papa, los padres Bayle, Leturia y Mateos unánimemente afirman que de seguro fue aprobatoria. Sus argumentos se basan, en primer lugar, en el hecho de que los obispos hispanoamericanos no hicieron nuevamente presente al monarca su deber de conciencia en los dos períodos posteriores del Concilio de Trento; y, en segundo, en que en las muchas veces que los padres conciliares trataron de compeler, aun con censuras eclesiásticas, a los obispos morosos para que acudieran en persona al Concilio o mandaran sus procuradores, nunca aparece la menor alusión a los obispos de las Indias españolas, ni en las listas de los obispos ausentes que enviaron sus excusas para no asistir, aparece ningún obispo hispanoamericano ${ }^{33}$.

\subsection{Las expectativas conciliares de los obispos hispanoamericanos}

No obstante la prohibición real y la dispensa papal, hubo serios intentos de asistir a Trento. El primer obispo de Michoacán, Vasco de Quiroga, quería, a pesar de todo, participar personalmente en el Concilio. Por esta razón se preparó y tomó el barco para España en 1543. Sin embargo, por los graves defectos en su embarcación, tuvo que renunciar el viaje iniciado y regresar al puerto. Juan de Zumárraga, obispo de México se conformó con enviar como comisionado suyo al agustino Juan de Oseguera con una lista de dudas y asuntos que debía proponer al Concilio o al Consejo de Indias. Sin embargo, el enviado fue interceptado en España, por lo tanto estas dudas nunca llegaron a Trento sino se vieron en el Consejo ${ }^{34}$. Más tarde, antes del comienzo del tercer período conciliar, el primer obispo de Popayán, Juan del Valle, acometió un último intento de llegar hasta Roma y después hasta el Concilio de Trento. Como afirma Juan Friede en su obra sobre la vida del obispo (1961), Juan del Valle efectuó este viaje en forma clandestina, sin licencia del Consejo y contra los deseos de las autoridades. Sin embargo, en el año 1561,

\footnotetext{
32 Citado en Bayle, "El Concilio", 260-261; Leturia, "Por qué", 609; Mesa, Concilios y sínodos, 7; Tineo, Los Concilios Limenses, 146.

${ }_{33}$ Bayle, "El Concilio", 261; Leturia, "Por qué”, 609-610; Mateos, "Ecos de América”, 570.

${ }^{34}$ Bayle, "El Concilio", 261-263; Tineo, Los Concilios Limenses, 147-148.
} 
[...] yendo a la ciudad de Roma a tratar ciertos negocios importantes que le convenían con Su Santidad, yendo el dicho Obispo su camino, había fallecido en el Reino de Francia sin hacer testamento ${ }^{35}$.

La Corte de Madrid dio ordenes para que las autoridades buscaran los papeles que hubiera dejado el prelado y devolvieren a España cualquier carta que el dicho obispo hubiera escrito ${ }^{36}$.

¿Por qué insistieron tanto los prelados hispanoamericanos en intervenir directamente o por medio de sus procuradores en el Concilio de Trento? ¿Qué es lo que esperaban de esta participación? Para poder responder a estos interrogantes hay que revisar, ante todo, los asuntos que querían proponer.

El obispo de Guatemala, Francisco de Marroquín, escribió en mayo de 1537 al Consejo de Indias, para conseguir la aprobación real de asistir al Concilio de Trento:

Espero licencia de V. M. para me hallar en el Concilio, do se proveerán cosas necesarias para estas partes, que es nueva iglesia y hay necesidad de la componer como nueva esposa ${ }^{37}$.

Aunque sea un poco larga, vale la pena citar la lista del obispo de México, Juan de Zumárraga, que su procurador, Juan de Oseguera debía proponer al Concilio general o a los señores del Consejo de Indias, puesto que presenta muy detalladamente todos los temas y asuntos, esas "cosas necesarias para estas partes" que el prelado esperaba ver resueltos en el seno de la asamblea general:

1. Que excusen al obispo por no asistir.

2. Que se provea a las Indias, por la distancia, de legado pontificio con facultades omnímodas, o se busque modo de subsanar la imposibilidad de acudir a la Santa Sede en dispensaciones y absoluciones.

3. Que se ordene la uniformidad en administrar los sacramentos y acomodarles los mandamientos de la Iglesia.

4. Que sin caer en censuras los religiosos puedan declarar contra los que agravian a los indios.

5. Que se conceden indulgencias y privilegios a los que fuesen a conversiones.

6. Que se obligue a los superiores regulares a declarar quiénes son aptos para la evangelización, y no pueden estorbarles la ida.

7. Que se funde Universidad, por falta de letras.

8. Que a los clérigos allí se les obligue a vivir en comunidad bajo superior.

\footnotetext{
${ }^{35}$ Juan Friede, Vida y luchas de don Juan del Valle, primer obispo de Popayán y protector de indios (Popayán: Editorial Universidad, 1961), 265.

${ }^{36}$ Friede, Vida y luchas, 264; José Restrepo Posada, "El sínodo diocesano de 1556", Boletín de Historia y Antigüedades (1956): 489-490, 458-482, 480.

${ }^{37}$ Citado en Bayle, "El Concilio", 260; Leturia, "Por qué", 607; Mesa, Concilios y sínodos, 7.
} 
9. Que no se permita pasar clérigos sino muy probados.

10. Que se autorice a los obispos para recoger, aun contra la voluntad de sus padres, a los niños y niñas con frailes y monjas, por su mejor educación cristiana.

11. Que no se quite a los frailes aplicar a los indios 'algún piadoso castigo' y se les conceda alguacil con vara contra los faltones.

12. Que se aclare de oficio si es justo hacer esclavos de rescate.

13. Solicitar reliquias y un jubileo para las iglesias de Indias.

14. Que el Papa otorgue bula de composición para los agraviadores de indios en materia de esclavitud y otros desmanes.

15. Que si no hubiese concilio o se suspendiese por mucho tiempo, que todo esto aquí contenido, que se había de negociar en concilio, se negocie con el Papa, y S. M. dé tal favor para ello que se alcance la determinación de todas las cosas que aquí se pide, porque no estemos tanto tiempo en estas partes tan remotas vacilando en cosas tan importantes.

16. Que las resoluciones en los puntos propuestos sean claras y tajantes ${ }^{38}$.

Como se puede ver, los asuntos que el obispo de México quería presentar al Concilio general eran problemas muy concretos, de índole práctica, que habían surgido de la evangelización de las tierras nuevamente conquistadas: problemas en torno a la forma de la predicación de la fe a los naturales, a la protección de los indios frente a los agravios de los conquistadores o, más importante, a las relaciones con la Santa Sede.

En las Constituciones del primer sínodo de Santafé (Nuevo Reino de Granada), celebrado en el año 1556 por el obispo fray Juan de los Barrios, encontramos el siguiente mandato (Título 10, Capítulo 8):

Porque al tiempo que los Españoles entraron a conquistar este nuevo Reyno somos informados que huvieron mucha suma de oro, que tomaron a los Yndios naturales de él; y assí mismo les hicieren guerra. Y para saber si la tal guerra que se hizo a los Yndios fue justa, o no; y si poseen con justo título lo que les llevaron, assí de rancheos como de partes, o no - S. S. A., siendo conferido, y visto lo susodicho fue acordado por todos de comun parecer que se remita al Santo Concilio, y al Consejo Real de Yndias de Su Magestad, para que de allí se embie al Santo Concilio ${ }^{39}$.

Los temas que el obispo de Popayán, Juan del Valle quiso comunicar y tratar con el Sumo Pontífice y con el Concilio general, eran de la misma índole. El obispo tenía muchos problemas con los encomenderos que cobraban tributos muy altos de sus indios sin proporcionarles en cambio la enseñanza religiosa. Juan del Valle tomó varias disposiciones con el fin de proteger a los indios, lo que los encomenderos consideraron como una ofensiva general contra sus derechos. El obispo viajó a Santafé para tratar los asuntos personalmente con los oidores de la

\footnotetext{
${ }^{38}$ Citado en Bayle, “El Concilio”, 263-264; Tineo, Los Concilios Limenses, 148-149.

${ }^{39}$ Las Constituciones Sinodales fueron publicadas en: Mario Germán Romero, Fray Juan de los Barrios y la Evangelización del Nuevo Reino de Granada (Bogotá: A. B. C., 1960), 457-563.
} 
Real Audiencia, sin embargo, desesperado por la ineficiencia de todas sus gestiones y viéndose rechazado por las autoridades civiles, se vio obligado a volver a Europa para proseguir su acción en España, Roma o ante el Concilio de Trento ${ }^{40}$.

Con base en estos ejemplos se puede afirmar que lo que los obispos hispanoamericanos querían presentar al Concilio a toda costa era una serie de problemas, unos de carácter dogmático, otros de orden práctico y moral, que habían surgido de las dificultades prácticas que brotaban del encuentro y de la convivencia de culturas tan diferentes, y que eran de importancia vital para la propagación de la fe en las tierras recién descubiertas. Disputas acerca de problemas de difícil solución, tales como el mismo título de la conquista, el derecho de hacer guerra a los indios, las normas de convivencia entre los naturales de aquellas partes y los conquistadores, encomienda y servicio personal, la forma en que había de ser predicada la fe, las capacidades intelectuales de los indígenas, la norma que se debía guardar tanto en la instrucción religiosa como en la administración de los sacramentos, la relación entre la autoridad civil y eclesiástica o la cuestión del legado pontificio en las Indias españolas.

Sin embargo, estas dudas e inquietudes concretas acerca de asuntos religiosos, dentro del sistema del Patronato Real, correspondían a la jurisdicción de la autoridad civil. Por lo tanto se discutían en el Consejo de Indias o, si era necesario, se negociaban con el Papa pero a través de los embajadores del Rey español ante la Santa Sede. Este hecho explica por qué insistieron tanto algunos prelados hispanoamericanos, aún en contra de la prohibición real y de la dispensa papal, en participar personalmente en el Concilio o, por lo menos, en enviar con sus procuradores las listas de estos problemas a la asamblea general. Desesperados por las decisiones poco imparciales de la autoridad civil en asuntos religiosos, querían apelar a un foro eclesiástico del cual esperaban más competencia y prudencia en las materias de la fe.

Eso explica también por qué los monarcas españoles rechazaron tan rígidamente la asistencia al Concilio tanto de los prelados de estas iglesias como de sus procuradores. Aunque, para salvar las apariencias, los Reyes basaron esta prohibición en impedimentos objetivos tales como la enorme distancia, los peligros del viaje y la absoluta necesidad de la presencia de los prelados hispanoamericanos en sus diócesis, se considera que es más convincente buscar la razón de este rechazo definitivo en la relación problemática que la Corona mantenía con la Santa Sede. Los monarcas, celosos defensores de sus privilegios, no pudieron permitir que la Curia Romana interfiriera en sus asuntos internos, menos en un momento en el que tanto el poder político como el poder espiritual tenía pretensiones hegemónicas.

\section{Conclusiones}

Como quedó aclarado a lo largo de las páginas anteriores, la problemática de la ausencia de los obispos y de los temas hispanoamericanos en el Concilio de Trento sólo se puede entender si se examina más profundamente tanto el contexto histórico de la gran asamblea religiosa como las

\footnotetext{
${ }^{40}$ Bayle, "El Concilio", 262; Friede, Vida y luchas, 258; Restrepo, "El sínodo”, 479-480.
} 
expectativas que los prelados hispanoamericanos tenían. En la coyuntura especial de aquel momento histórico, el Concilio no pudo tener presente otros problemas sino los europeos. Frente a los desafíos del movimiento protestante, la Iglesia tuvo que aclarar su posición y, aceptando la ruptura ya irreversible de la coherencia de la comunidad sagrada del cristianismo, reconstruir una nueva unidad de la comunidad católica. En Trento, por lo tanto, no solamente se determinaron los cánones y dogmas de la fe católica que todos los fieles tenían que creer y confesar, sino se unificaron y se uniformizaron todos los momentos de la vida religiosa.

El modelo de catolicismo propuesto a partir de Trento iba más allá del dogma y de la liturgia. Era una tentativa colosal de orientar la política, de cambiar y uniformizar las conductas y las mentalidades de la población de la época e, incluso, de controlar la producción literaria y artística. Históricamente este fenómeno coincidía con el esplendor del absolutismo moderno. En el siglo XVI, entonces, existían, por un lado, unas monarquías expansivas, celosas de toda instancia alternativa de poder, dedicadas a controlar hasta los mínimos detalles de la vida de los súbditos, y, por el otro, la Iglesia católica que se dotaba de un programa que unía al deseo de guiar las conciencias de sus fieles una firme voluntad de conformar toda la sociedad.

Esta relación problemática entre la Iglesia y las monarquías absolutistas se manifestaba, como se vio, en cada aspecto del Concilio de Trento. La elección del lugar del concilio; la temática conciliar, o sea, la cuestión de ser un concilio de reforma o un concilio doctrinal; el traslado del concilio a Bolonia, a una ciudad de los Estados de la Iglesia, tras la victoria decisiva de Carlos V sobre los estamentos protestantes; el debate sobre la necesidad de la confirmación papal de los decretos conciliares y la discusión fundamental que se escondía detrás de este problema protocolario, a saber, la cuestión del liderazgo de la reforma tridentina, todos remitían a esta problemática de las relaciones entre el poder político y el poder espiritual en la Europa moderna.

La aceptación y la aplicación de los decretos tridentinos eran obligatorias para todos los países católicos. Según la bula Benedictus Deus desde ahora en adelante la tarea era conformar la vida de la Iglesia, o sea, de toda la comunidad sagrada con las decisiones dogmáticas y disciplinares tomadas en el Concilio de Trento. Sin embargo, los poderes seculares veían con mucho recelo tanto ciertos decretos tridentinos como la pretensión hegemónica papal. Por lo tanto, muy pronto se planteaban en muchos reinos europeos disputas por la interpretación y la ejecución del Concilio, aunque quizás de forma más sutil en la Monarquía Hispana. En teoría, pues, Felipe II, con la pragmática del 12 de julio de 1564, aceptó íntegramente el Concilio; en la práctica, sin embargo, se desplegó una acción política que alternaba el apoyo decidido a la reforma tridentina en muchos aspectos con la reticencia, cuando no la franca negativa, a la ejecución de ciertos decretos.

La Monarquía Hispana era uno de los países de aspiraciones absolutistas donde el control del Estado sobre la Iglesia tenía tradiciones muy fuertes. En la Península Ibérica, desde el siglo XV se fue lentamente organizando una estructura político-jurídica de dominación sobre la Iglesia, una dominación que quizás nunca ninguna monarquía ejerció a tal punto. Las relaciones entre la 
Iglesia y el Estado, pues, en todos los territorios de la Corona española fueron gobernadas por el Patronato Real o sistema de real patronazgo, según el cual la Iglesia de Roma les delegaba sus poderes espirituales y temporales a los Reyes de España. En la América española, a partir de 1524, los poderes otorgados a la Corona fueron ejercidos por el Consejo Real y Supremo de las Indias, que se convirtió en el órgano supremo, la autoridad última de la cristiandad de las Indias españolas, que ejercía al mismo tiempo el gobierno eclesiástico y civil de América ${ }^{41}$.

Como se vio con base en la documentación presentada, los asuntos que los obispos hispanoamericanos esperaban presentar al Concilio de Trento, dentro del Patronato Real, correspondían a la jurisdicción de la autoridad civil y, por lo tanto, se discutían en el Consejo de Indias o, si era necesario, se negociaban con el Papa pero a través de los embajadores del Rey español ante la Santa Sede. No era de sorprender, entonces, que los monarcas españoles, celosos defensores de sus privilegios, prohibieran a toda costa la participación directa tanto de los prelados como de los procuradores de estas iglesias en la asamblea religiosa. Los Reyes de España, en última, no pudieron permitir que la Curia Romana interfiriera en sus asuntos internos.

Así, pues, ni los temas ni los representantes de las iglesias hispanoamericanas estuvieron presentes en el Concilio de Trento. Sin embargo, también ellas tenían que aceptar y aplicar los decretos tridentinos en sus territorios. ¿Cómo pudieron aplicar estas decisiones enteramente europeas en las circunstancias especiales del Nuevo Mundo? ¿Cómo se modificaron estos decretos según las necesidades singulares de los territorios americanos? ¿Cómo modificó el mismo Patronato Real, o sea, la política eclesiástica de Felipe II estos decretos en la América española? ¿El Patronato funcionó de la misma manera en la Península y en las Indias españolas? Son preguntas que inmediatamente surgen del estudio detallado de las razones de la ausencia de las iglesias hispanoamericanas en Trento, es decir, de la paradoja que esta falta de representación causaba en cuanto a la aplicación de los decretos en el Nuevo Mundo. Preguntas que vale la pena ser investigadas más profundamente, sobre todo, porque la influencia del Concilio de Trento en la América española no constituye un terreno muy elaborado por los historiadores.

\footnotetext{
${ }^{41}$ Dussel, Historia General, 242.
} 


\section{Bibliografía}

Anderson, Benedict. Comunidades imaginadas: reflexiones sobre el origen y la difusión del nacionalismo. México: Fondo de Cultura Económica, 1993.

Aparicio, Severo. "Influjo de Trento en los Concilios Limenses". Missionalia Hispanica, no. 29 (1972): 215-239.

Barraza M., Martín. Valor magisterial del secreto de la justificación (sesión sexta del Concilio de Trento). Bogotá: Pontificia Universidad Javeriana, 1959.

Bayle, Constantino. "El Concilio de Trento en las Indias Españolas", Razón y Fe, no. 564 (1945): 257-284.

Christiani, Leon (dir.). Trento. Valencia: Edicep, 1976.

Delumeau, Jean. El Catolicismo de Lutero a Voltaire. Barcelona: Editorial Labor, 1973. . La reforma. Barcelona: Editorial Labor, 1977.

Derisi, Octavio Nicolás. "La significación filosófica del Concilio de Trento y la edad moderna, 1545-1945", Colegio Mayor de Nuestra Señora del Rosario 396 (1946).

Dussel, Enrique (dir.). Historia General de la Iglesia en América Latina, Tomo I/1, Introducción general. CEHILA, Ediciones Sígueme, 1983.

El Sacrosanto y ecuménico Concilio de Trento, traducido al idioma castellano por Ignacio López de Ayala. Agregase el texto original corregido según la edición auténtica de Roma, publicada en 1564. Madrid, 1785.

Fernández Terricabras, Ignasi. Felipe II y el clero secular. Aplicación del Concilio de Trento. Madrid: Sociedad Estatal para la Conmemoración de los Centenarios de Felipe II y Carlos V, 2000.

Friede, Juan. Vida y luchas de don Juan del Valle, primer obispo de Popayán y protector de indios. Popayán: Editorial Universidad, 1961.

Groot, José Manuel. Historia eclesiástica y civil de Nueva Granada, 5 vols. Bogotá: A. B. C., 1953.

Jedin, Hubert. El Concilio de Trento en su última etapa. Crisis y conclusiones. Barcelona: Herder, 1965.

Historia del Concilio de Trento, tercer periodo de sesiones y conclusiones, 2 vols. Pamplona: EUNSA, 1981.

Jedin, Hubert (dir.). Manual de Historia de la Iglesia, Reforma, reforma católica y contrarreforma.Tomo V. Barcelona: Herder, 1966.

Lebroc, Reynerio. "Proyección tridentina en América". Missionalia Hispanica, no. 77 (1969): 129-207.

Leturia, Pedro de. "Por qué la naciente iglesia hispanoamericana no estuvo representada en Trento", en Leon Cristiani (dir.). Trento. Valencia: Edicep, 1976, 603-615.

Lisi, Francesco Leonardo. El Tercer Concilio Limense y la aculturación de los indígenas sudamericanos. Estudio crítico con edición, traducción y comentario de las actas del concilio provincial celebrado en Lima entre 1582 y 1583. Salamanca: Gráficas Varona, 1990. 
Llorca, Bernardino. "La reforma disciplinar de la Iglesia y el Concilio de Trento". Razón y Fe, no. 564 (1945).

Marchena Fernández, Juan. La jerarquía de la Iglesia en Indias: el episcopado americano, 1500-1850. Madrid: MAPFRE, 1992.

Mateos, Francisco. "Los dos concilios Limenses de Jerónimo de Loaysa". Missionalia Hispanica, no. 12 (1947): 479-524.

"Ecos de América en Trento", en Leon Cristiani (dir.). Trento. Valencia: Edicep, 1976: 565-599. Publicado por primera vez en: Revista de Indias, no. 22 (1945): 559605.

Mesa, Carlos E. Concilios y sínodos en el Nuevo Reino de Granada, hoy Colombia. Madrid: Raycar, 1974.

Navas Gutiérrez, Antonio M. "Trento: algunas lecciones de un gran concilio", Proyección, no. 179 (1995): 259-271.

Ortega Mariano, Martín. “450 años del Concilio de Trento, 1545-1563”, Religión y Cultura, no. 193 (1995): 245-279.

Pinilla Cote, Alfonso María. "El Concilio de Trento y la unidad religiosa", Revista Javeriana, no. 271 (1961).

Restrepo Posada, José. "La evangelización del Nuevo Reino (siglo XVI)", Historia Extensa de Colombia. Volumen 13. Bogotá: Lerner, 1971.

Romero, Mario Germán. Fray Juan de los Barrios y la Evangelización del Nuevo Reino de Granada. Bogotá: A. B. C., 1960.

Schatz, Klaus. Los concilios ecuménicos. Encrucijadas en la historia de la Iglesia. Valladolid: Trotta, 1999.

Tineo, Primitivo. Los Concilios Limenses en la evangelización latinoamericana. Labor organizador del Tercer Concilio Limense. Pamplona: Universidad de Navarra, 1990.

Villegas, Juan de. Aplicación del Concilio de Trento en Hispanoamérica, 1564-1600. Montevideo: Instituto Teológico del Uruguay, 1975.

Zagheni, Guido. Curso de Historia de la Iglesia, La Edad Moderna. Madrid: San Pablo, 1997. 